\title{
Performance for Justice Perception Framework Analysis on Digital Music Service
}

\author{
Nanang Husin ${ }^{1}$ and Achmad Nizar Hidayanto ${ }^{2}$ \\ \{nangryo@gmail.com¹,nizar@cs.ui.ac.id²\} \\ ${ }^{1,2}$ Computer Science Faculty University of Indonesia, Indonesia
}

\begin{abstract}
Nowadays, although digital music service is growing, still goes pale compared to the peak of physical music era. Many problems arise from the unreadiness of the music industry, failed attempt to capture of what user needs to the miss-understanding of the complexity of the digital music piracy. And those led to the loss of much billion-dollar revenue and opportunity. The goals of this research are to find out about how user behavior according to their perceived level of fairness with the digital music service using justice perception framework theories.
\end{abstract}

Keywords: digital music service, justice perception framework, performance analysis

\section{Introduction}

Before the music industry entered the digital age, music sales in the world were dominated in physical form. However, the presence of MP3 digital formats and the development of Internet networks in the community led to the transition of music sales from physical format to digital format. The transformation of the music industry brought about a lot of changes, unfortunately, many of its players in the music industry are not ready.

Demand for digital music has grown staggeringly as MP3 replaces compact disc (CD) as a preferred music format. As of $2010,47 \%$ of total US music shipments are accounted for digital music, a huge increase from 9\% in 2005 (Friedlander, 2010). But the fall is actually followed up by an increased in digital music sales. From 2010 to 2014 the sale is down almost $40 \%$ but the revenue of digital music sales is up to almost 53\%. Those account for 1192.3 million-dollar increased sales (Athina et al, 2017).

Many digital music services are growing and failing. From music file sharing like Napster and Kazaa to music streaming/shop like last.FM, Zune Marketplace, and so on. Some succeed at the beginning and then decline, and others never get enough users to continue their service (Alves, 2005). To be able to offer a viable digital music service, we need to adhere what users want.

There are quite a lot of research on the transformation of this digital music. There are research's that highlights on user behavior in the pirating and purchasing of digital music as did Theodore Giletti in his dissertation. His research shows that majority of people are willing to pay for digital music, yet they are discouraged by the existence of legal threats. Users also not subscribing to music streaming service despite being satisfied with it. Younger audiences favor pirating music even though it infringes copyright laws as they believe the freedom of the internet. This drives the music industry and music artist themselves to fight digital piracy and encourages people to pay for digital music. Cheolho Yoon on his research tries to study user behavior on digital piracy which includes digital music in it. It shows that moral obligation and justice, using ethics theories combined TPB variables, such as attitude, subjective norms, 
and perceived behavioral control has an influence on the behavioral intentions to commit digital piracy. It also influenced by perceived benefits, perceived risk, and habit (Yoon, 2011). Szewan on his research used TPB combined with TAM to analyze user behavior to use digital music service. It shows that perceived behavioral control all have positive effects on behavior intention (the TPB portion), whilst perceived usefulness and perceived ease of use both have positive effects on attitude, with perceived ease of use having a positive effect on perceived usefulness (the TAM portion) (SzeWan Kwong, 2006).

This paper tries to analyze user behavior on Digital Music offering by using Perception of Justice of fairness framework to give more insight about the problem on digital music service on digital music transformation since currently no other research directly studies about it.

The research based on Vincente Justice Perception on user satisfaction research model. The modified model used perceived model on customer satisfaction aimed at digital music service offering, whether it's Digital Music store or streaming service to study which dimension of perceived justice affect the customer's fairness level the most, and which factor in each dimension has the most performance in effect.

\section{Previous Study}

Justice or fairness represent to the idea that action or decision is right which defined according to ethics, religion, fairness, equity or law. Organizational justice describes of person or groups perception of fairness (justice) that they received from an organization, and how they perceived and react to those treatments. It has three main proposed components, which include distributive justice, procedural justice, and interactional justice. Those three main components are correlated and can be seen as three components of overall fairness

Organizational justice describes the individual's and the group's perception of the fairness of treatment received from an organization and their behavioral reaction to such perceptions.

Three main proposed components of organizational justice are distributive, procedural, and interactional justice (which includes informational and interpersonal justice). Distributive, procedural, and interactional justices are correlated. They can be meaningfully treated as three components of overall fairness (Silva \& Madhumali, 2014)

Three dimensions of perceived justice have been proposed as a direct factor for customer satisfaction, which is Distributive justice (perceived fairness of outcomes), Procedural justice (the perception that fair procedures were used to arrive at outcomes), Interactional justice (perceived fairness of interpersonal treatment).

When three of those perceived justices is fulfilled, it can rest assured that user will be satisfied with the service/treatment. But in practice, not all justice condition can be met.

Which justice that should be prioritized is varied depends on the field and situation.

Each of them has injustice factor that can affect users/member perceived fairness

For Distributive injustice, it has unfavorable quality/price ratio, feeling of "having been cheated", the feeling of wasted time, and differential treatment factor. For Procedural injustice, it has the misuse of power, dishonesty (laws, contracts or commitments), the absence of commercial favor, and retention\& misinformation problems factor. For Interactional injustice, it has bad faith, lack of respect, lack of understanding, and listening/empathy factor (Aurier \& Béatrice, 2007). This differentiation is well established, not just in the study of consumer behavior, but also in other research areas such as organizational justice (Vicente et al, 2006). 
Some studies focused only one dimension of justice, the others did not distinguish between these three dimensions, despite the fact that differentiating these three dimensions of justice gives a richer outcome of the relationship between justice and customer satisfaction.

So, Digital Music can be seen as a product (outcome oriented) or service (relationshiporiented). By using justice instrument as an evaluation tool, we can predict customer satisfaction on both sides. From Vincent study of justice perceptions related to customer satisfaction, the given result is as follow

Distributive justice (DJ) was measured on a scale that assesses the degree to which outcomes are perceived to be related to inputs (Tata \& Bowes-Sperry, 1996).

Table 1. Distributive Justice variable

\begin{tabular}{rll}
\hline No. & Variable Name & Label \\
\hline 1 & Quality has given by price & V1 \\
\hline 2 & Services and feature/facilities correspond to the price & V2 \\
\hline 3 & The price is appropriate & V3 \\
\hline 4 & Different price for the same service & V4 \\
\hline
\end{tabular}

Procedural justice $(\mathrm{PJ})$ variable is a reverse-scored item to measure procedural justice, reflecting the waiting time and accessibility of employees (Blodgett et al., 1997):

Table 2. Procedural Justice variable

\begin{tabular}{rll}
\hline No. & Variable Name & Label \\
\hline 1 & Time to attend an inquiry & V5 \\
\hline 2 & Lack of good faith & V6 \\
\hline 3 & Duration of service problem solving & V7 \\
\hline 4 & Difficulty to get in touch with customer & V8 \\
\hline
\end{tabular}

Interactional justice (IJ) was measured using a three-item scale that assesses how much employees provided customers with caring and individual attention (Hocutt et al., 1997):

Table 3. Interactional Justice variable

\begin{tabular}{rll}
\hline No. & Variable Name & Label \\
\hline 1 & Understanding of customers need & V9 \\
\hline 2 & Personal attention to service & V10 \\
\hline 3 & All out respond to customer service & V11 \\
\hline
\end{tabular}

Customer satisfaction (CS) was measured by using a scale that assesses satisfaction and feelings about the choices (Mano \& Oliver, 1993)

Table 4. Customer Satisfaction variable

\begin{tabular}{rll}
\hline No. & Variable Name & Label \\
\hline 1 & Fairness fulfilled & V12 \\
\hline 2 & The future decision regarding a service & V13 \\
\hline
\end{tabular}

Digital music can be seen as hedonic or utilitarian. Generally, we see people buy products based on their needs, yet everyone has distinct desires on what they want from a product. When people buy products based on their need for basic function, it is a utilitarian 
consumption, and when people buy them with consideration of pleasure and excitement experiences, it is hedonic consumption (Giuliana, José \& Angelika, 2017).

People saw more price unfairness when paying more for the utilitarian product in comparison to when it was a hedonic product. However, when compared to hedonic products, the perception of price unfairness decreased. These studies show people react differently on price changes for hedonic and utilitarian products based on their presentation, as subjects who stimulated by photo saw more unfairness on price change of utilitarian products compared to hedonic products (Giuliana, José \& Angelika, 2017). Digital music is basically also a product, so digital music can be positioned as a hedonic or functional utilitarian product.

Although MP3 format already published in 1993, it's not until 1998 when digital music really gains its growth, with the evolution of the MP3 player on the market (Sadie, 2010). Total revenue from U.S. music sales and licensing plunged to $\$ 6.3$ billion in 2009 , whereas in 1999 , that revenue figure is topped at $\$ 14.6$ billion $(\mathrm{CNN}, 2010)$. By understanding those nature, it's curious to try to see whether it's true that quality of the streaming service/digital music file didn't affect the user to pay for it compared if they can get it free via legal manners or piracy. Although arguably, consumers value digital music is less valuable than the physical product (Styven, 2010).

\section{Methodology}

In this paper, quantitative research is done using a Justice Perception Framework Factor from music as hedonic or utilitarian and piracy factor also added to enrich the study. Indicator for each variable on Vicente research is given to try to find how customer satisfaction with Digital Music Service offering. Variables of each Justice are then given an indicator as follow :

Table 6. Distributice Justice variable to indicator

\begin{tabular}{|c|c|c|c|}
\hline No. & $\begin{array}{l}\text { Variable } \\
\text { Label }\end{array}$ & Indicator & $\begin{array}{l}\text { Indicator } \\
\text { Label }\end{array}$ \\
\hline 1 & V1 & $\begin{array}{l}\text { Prices for streaming services or digital files are in line with } \\
\text { their quality }\end{array}$ & D1 \\
\hline 2 & V2 & $\begin{array}{l}\text { Using a streaming/buying music service is more valuable than } \\
\text { getting music for free (legal or illegal) }\end{array}$ & D2* \\
\hline 3 & V3 & The streaming/selling service of digital music is useless to you & D3 \\
\hline 4 & V4 & $\begin{array}{l}\text { The service of streaming/selling digital paid files with different } \\
\text { levels of service quality with different price is preferred (egg } \\
\text { silver member can only listen to lossy but very cheap cost, a } \\
\text { golden member can choose losslessly and all collection but } \\
\text { expensive) }\end{array}$ & $\mathrm{D} 4 * *$ \\
\hline
\end{tabular}

Table 7. Procedural Justice variable to indicator.

\begin{tabular}{clll}
\hline No. & $\begin{array}{l}\text { Variable } \\
\text { Label }\end{array}$ & Indicator & $\begin{array}{l}\text { Indicator } \\
\text { Label }\end{array}$ \\
\hline 1 & V5 & $\begin{array}{l}\text { Digital music streaming/sales service that likes to alter its } \\
\text { sales package without notice is clearly not preferred }\end{array}$ & P1 \\
\hline 2 & V6 & $\begin{array}{l}\text { Digital music streaming/sales service that does not match } \\
\text { descriptions is disliked (for example in the advertisement } \\
\text { the service is lossless but it is only for some albums only) }\end{array}$ & P2 \\
\hline 3 & V7 & Inexpensive digital music streaming/sales service is hard & P3 \\
\hline
\end{tabular}




\begin{tabular}{llll}
\hline \multicolumn{4}{l}{ to contact when problems occur } \\
\hline 4 & V8 & $\begin{array}{l}\text { Digital music streaming/sales service that is not } \\
\text { clear/convoluted }\end{array}$ & P4 \\
\hline
\end{tabular}

Table 8. Interactional Justice variable to indicator.

\begin{tabular}{clll}
\hline No. & $\begin{array}{l}\text { Variable } \\
\text { Label }\end{array}$ & Indicator & $\begin{array}{l}\text { Indicator } \\
\text { Label }\end{array}$ \\
\hline 1 & V9 & $\begin{array}{l}\text { The customer service part of an online streaming service / } \\
\text { digital music sales often does not provide a solution when a } \\
\text { problem occurs }\end{array}$ & I1 \\
\hline 2 & V10 & $\begin{array}{l}\text { Customers of digital music/music streaming services often } \\
\text { feel underappreciated when long enough to subscribe but no } \\
\text { more services }\end{array}$ & I2 \\
\hline 3 & V11 & $\begin{array}{l}\text { Customers of digital music/music streaming services are } \\
\text { often not considered/responded to when they get into trouble }\end{array}$ & I3 \\
\hline
\end{tabular}

Table 9. Customer Satisfaction variable indicator.

\begin{tabular}{rlll}
\hline No. & Variable Label & Indicator & Indicator Label \\
\hline 1 & V12 & You are likely to buy digital music file & BDM \\
\hline 2 & V13 & You are a regular user of music streaming services & SDM \\
\hline
\end{tabular}

D2 are the question based on distributive injustice factors combined with a study about digital music piracy, and D4 are questioned also based on distributive injustice combined with music as a hedonic or utilitarian product.

The model modified to reflect the relationship of user satisfaction with Digital Music service offering. The model is based on Vicente justice model with the addition of injustice factor from Aurier. The model is as follow:

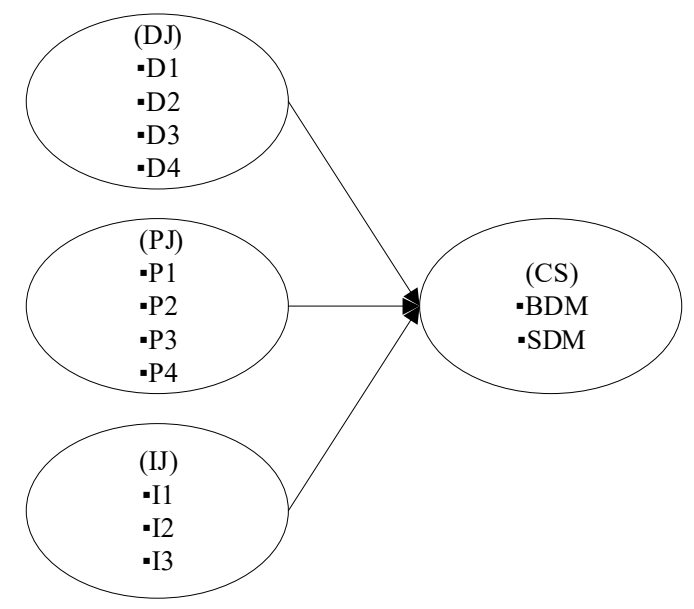

Figure 1: Justice Perception Model to Customer Satisfaction

The aim of this model is to find out which dimension of justice has the most effect on customer satisfaction/fairness, and which factor has the most significant relationship. 
Each variable then is given a corresponding hypothesis as follow

H1: Positive association of D1 to CS

H2: Positive association of D2 to CS

$\mathrm{H} 3$ : Negative association of D3 to CS

H4: Positive association of D4 to CS

H5: Positive association of $\mathrm{P} 1$ to $\mathrm{CS}$

H6: Positive association of $\mathrm{P} 2$ to $\mathrm{CS}$

H7: Negative association of P3 to CS

H8: Positive association of $\mathrm{P} 4$ to $\mathrm{CS}$

H9: Negative association of I1 to CS

H10: Negative association of 12 to CS

H11: Negative association of I3 to CS

The tool used to collect primary data in this study is a questionnaire. The scale used in this research is Likert scale using five scales from Strongly disagree from the lowest number to the Strongly Agree to the highest. The questionnaire is done online conducted via survey monkey, given to audio enthusiast member of "KereHore" (https://www.facebook.com/groups/audiokerehore/about/), a group based on Facebook with more than 50 thousand members. The data collected at the time of analysis is 75 participants. All 75 surveyors fill all the questioner, however, four of them failed the manipulation check test. So only 71 data are used $(94 \%)$.

The reason this group is chosen because they are regularly deal with digital music in their daily life. And this group has a broad selection of member which could give a great data diversity. We inserted two manipulation check question to increase the validity of the test result, one is in the user profile question, and the other one is in the research question.

The data analysis was done using AMOS SPSS Application to test the relationship between the effects of one variable to another variable using regression technique. Validity test is done before the regression test by almost to make sure whether the questioner in research instrument is accurate and valid so it can measure what it should while A reliability test using Cronbach's Alpha Internal Consistency is also used to see the data has a good consistency. In this research, we use SPSS software to measure each of the questioner items.

\section{Result \& Discussion}

Validity test result shows that Based on this test, BDM, D3, I2 r value is below value table at $\mathrm{N}=71(0,2335)$ so they forfeited.

Reliability test result shows that I2 has scored below Cronbach's alpha value limit which is 0.5 , so it is unacceptable and will not be used. So, after validity and reliability test, only SMD, D1, D2, D4, P1, P2, P3, P4, I1, I3 pass both tests so they will be used on the AMOS regression test whilst $\mathrm{BDM}, \mathrm{D} 3$ and $\mathrm{I} 2$ are forfeited.

Below is the model for AMOS test 


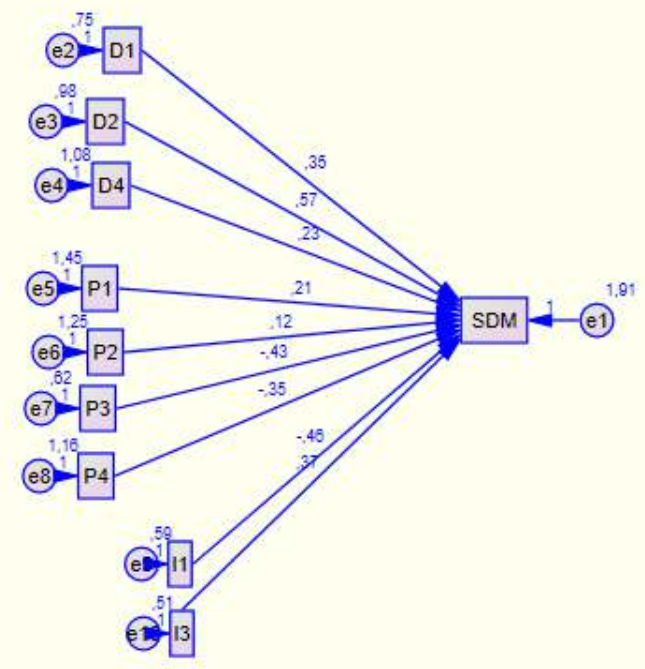

Figure 2: Amos test model

It is shown that the indicator used is down from 11 to nine because of the validity and reliability test.

Table 10. Regression Weights: (Group number 1 - Default model)

\begin{tabular}{rlrrrrr}
\hline \multicolumn{1}{c}{} & & & Estimate & S.E. & C.R. & P \\
\hline SDM & $<---$ & D1 & 0,349 & 0,19 & 1,835 & 0,067 \\
\hline SDM & $<---$ & D2 & 0,567 & 0,166 & 3,41 & $* * *$ \\
\hline SDM & $<---$ & D4 & 0,232 & 0,158 & 1,462 & 0,144 \\
\hline SDM & $<---$ & P1 & 0,207 & 0,137 & 1,513 & 0,13 \\
\hline SDM & $<---$ & P2 & 0,125 & 0,148 & 0,844 & 0,399 \\
\hline SDM & $<---$ & P3 & $-0,43$ & 0,21 & $-2,051$ & 0,04 \\
\hline SDM & $<---$ & P4 & $-0,345$ & 0,153 & $-2,257$ & 0,024 \\
\hline SDM & $<---$ & I1 & $-0,464$ & 0,215 & $-2,163$ & 0,031 \\
\hline SDM & $<---$ & I3 & 0,375 & 0,231 & 1,623 & 0,104 \\
\hline
\end{tabular}

C.R above shows the critical ratio value obtained from the estimated value which is divided by the standard error (S.E). The higher the C.R value the more significant. If the sample size is large, then usually the value of C.R above 1.96 will be resulting in a significant estimated value at the $5 \%$ level, whereas if above 2.56 will be significant at $1 \%$ level. In this case, only D2 shows significance with SDM in the test, hence H2: Using a streaming / buying music service is more valuable than getting music for free (legal or illegal) has a great effect on Perceived of Fairness to buy is proven

From this research can be seen from D2 factors that users do still value a good digital music file offering or streaming service. It just the matter of how they put the value on the service. Unfortunately, D4 factor cannot be tested because of data validity and reliability problem. The other factors didn't have a significant effect on Perceived of Fairness to buy digital music file or subscription service. 
By looking the responded profile, it can be seen that majority of the users are quite well educated, although they don't have much money to spare because they are on the minimum wage level of salary. And although they rarely buy digital music file, surprisingly the majority of them does use digital music streaming service. It means that majority users prefer the digital music streaming service than buying digital music file, or it means there still quite a lot of room for digital music file shop to grow. After understanding this result, those in the music industry could react accordingly

\section{Conclusion}

There is one main significant factor that has strong performance in influencing Perceived of Fairness to buy digital music file or service, which is (D2) Feeling of "having been cheated" which combined with the factor of piracy and translated to question

Using a streaming/buying music service is more valuable than getting music for free (legal or illegal). The other factor did not have much influence on the perceived of fairness.

For those in the music industry, if they could be understanding the result of this research they could take the necessary step to change and take the opportunity of the growing digital music business. The best way is to combine not just from one research, but several of them, to see what is much in common and take a creative action with it, not to just blame the piracy and stay the same. The digital music industry is taking shape and evolving. The final product of what called ultimate digital music service is not yet come. This research has shortcomings which come from its data source. The data is limited because of the time constraint and resource. With more and better quality of data, the result can be much better. There some suggestions that should be taken note for the future research, which is increased samples size, and by tuning and increasing the questionnaire item. It will yield a better informed and rich result

\section{References}

[1] Athina Dilmperi, Tamira King \& Charles Dennis (2017), "Toward a Framework for Identifying Attitudes and Intentions to Music Acquisition from Legal and Illegal Channels", Psychology \& Marketing, Vol. 34(4): 428-447

[2] Aurier Philippe \& Béatrice Siadou-Martin (2007), "Perceived justice and consumption experience evaluations: A qualitative and experimental investigation", International Journal of Service Industry Management Vol. 18 No. 5, pp. 450-471

[3] Blodgett, J. G., Hill, D. J., \& Tax, S. S. (1997). The effects of distributive, procedural, and interactional justice on post-complaint behavior. Journal of Retailing, 73, 185-210.

[4] Cheolho Yoon (2011), "Theory of Planned Behavior and Ethics Theory in Digital Piracy: An Integrated Mode", Journal of Business Ethics (2011) 100:405-417

[5] CNN Money, "Music's lost decade: Sales cut in half". Retrieved from: http://money.cnn.com/2010/02/02/news/companies/napster_music_industry/

[6] Friedlander, J. P. (2010). "News and Notes on 2010 RIĀA Músic Shipment Data". Retrieved from: http://76.74.24.142/548C3F4C-6B6D-F702-384CD25E2AB93610.pdf

[7] Giuliana Isabella,José Afonso Mazzon \& Angelika Dimoka (2017), "Impacts of product type and representation type on the perception of justice and price fairness", Journal of Business Research 81 (2017) 203-211 
[8] H. M. S. V. Silva \& K. P. W. C. Madhumali (2014), "Organizational Justice and Organizational Citizenship Behavior: A Study of Public Sector Organizations in Western Province, Sri Lanka"

[9] Katina Michael \& K. Alves (2005), "The Rise and Fall of Digital Music Distribution Services: a Cross-Case Comparison of MP3.com, Napster and Kazaa", Proceedings of the Collaborative Electronic Commerce Technology and Research Conference LatAm, University of Talca, Chile, 3-5 October 2005, 1-22.

[10] Luo, Y. (2007), "The independent and interactive roles of procedural, distributive, and interactional justice in strategic alliances", Academy of Management Journal, 50(3), 644-664.

[11] Mano, H., \& Oliver, R. L. (1993). Assessing the dimensionality and structure of the consumption experience: Evaluation, feeling, and satisfaction. Journal of Consumer Research, 20, 451-466.

[12] Sadie A. Stafford (2010),"Music in the Digital Age: The Emergence of Digital Music and Its Repercussions on the Music Industry", The Elon Journal of Undergraduate Research in Communications, Vol. 1, No. 2, pp 113

[13] Styven, M. E. (2010) The need to touch: Exploring the link between music involvement and tangibility preference. Journal of Business Research, 63, 1088-1094.

[14] SzeWan Kwong, JungKun Park \& Sujin Yang (2006),"Consumer Choice of Digital Music Services from Quality Perceptions", Service Operations and Logistics, and Informatics, 2006. SOLI '06. IEEE International Conference

[15] Tata, J., \& Bowes-Sperry, L. (1996). Emphasis on distributive, procedural, and interactional justice: Differential perceptions of men and women. Psychological Reports, 79, 1327-1330.

[16] Theodore Giletti (2012), "Why pay if it's free? Streaming, downloading, and digital music consumption in the iTunes era", Dissertation of London School of Economics and Political Science ("LSE")

[17] Vicente et all, (2006), "Justice Perceptions as Predictors of Customer Satisfaction: The Impact of Distributive, Procedural, and Interactional Justice", Journal of Applied Social Psychology, 2006, 36, 1, pp. 100-119 